\title{
The Role of Psychological Stress in Inflammatory Bowel Disease: Quality Assessment of Methods of 18 Prospective Studies and Suggestions for Future Research
}

\author{
Rafael J.A. Cámara ${ }^{\mathrm{a}} \quad$ Roger Ziegler $^{\mathrm{b}} \quad$ Stefan Begré $^{\mathrm{a}} \quad$ Alain M. Schoepfer $^{\mathrm{c}}$ \\ Roland von Känel ${ }^{a}$ \\ Swiss Inflammatory Bowel Disease Cohort Study (SIBDCS) group \\ ${ }^{a}$ Department of General Internal Medicine, Division of Psychosomatic Medicine, Bern University Hospital and \\ University of Bern, and ${ }^{b}$ Department of Psychiatry, University of Bern, Bern, Switzerland; ${ }^{~}$ Farncombe Family \\ Institute of Digestive Health Research, McMaster University, Hamilton, Ont., Canada
}

\section{Key Words}

Crohn's disease $\cdot$ Ulcerative colitis $\cdot$ Psychological stress

\begin{abstract}
Background: Enquiries among patients on the one hand and experimental and observational studies on the other suggest an influence of stress on inflammatory bowel diseases (IBD). However, since this influence remains hypothetical, further research is essential. We aimed to devise recommendations for future investigations in IBD by means of scrutinizing previously applied methodology. Methods: We critically reviewed prospective clinical studies on the effect of psychological stress on IBD. Eligible studies were searched by means of the PubMed electronic library and through checking the bibliographies of located sources. Results: We identified 20 publications resulting from 18 different studies. Sample sizes ranged between 10 and 155 participants. Study designs in terms of patient assessment, control variables, and applied psychometric instruments varied substantially across studies. Methodological strengths and weaknesses were irregularly dispersed. Thirteen studies reported significant relationships between stress and adverse
\end{abstract}

outcomes. Conclusions: Study designs, including accuracy of outcome assessment and repeated sampling of outcomes (i.e. symptoms, clinical, and endoscopic), depended upon conditions like sample size, participants' compliance, and available resources. Meeting additional criteria of sound methodology, like taking into account covariates of the disease and its course, is strongly recommended to possibly improve study designs in future IBD research.

Copyright $\odot 2009$ S. Karger AG, Basel

\section{Introduction}

\section{What Is Stress?}

From a medical point of view, stress is best conceptualized as a three-level cascade initiated by stressors from the environment and the 'milieu intérieur' (first level). Two types of stressors can be distinguished being physical stressors such as pain, cold, or exhaustion and psychological stressors such as negative life experiences of different quality and quantity. Stress perception, i.e. the development of stressful feelings ('distress'; second level), is determined by the subjective meaning someone attri-

\section{KARGER}

Fax +41613061234 E-Mail karger@karger.ch www.karger.com (c) 2009 S. Karger AG, Basel

$0012-2823 / 09 / 0802-0129 \$ 26.00 / 0$

Accessible online at:

www.karger.com/dig
Rafael J.A. Cámara, MD

Department of General Internal Medicine, Division of Psychosomatic Medicine Bern University Hospital, Inselspital, Freiburgstrasse

$\mathrm{CH}-3010$ Bern (Switzerland)

Tel. +41 3163245 74, Fax +41 3138211 84, E-Mail rafael.camara@insel.ch 
butes to a stressor and the appraised coping strategies to deal with threat and challenge [1]. Stress perception is influenced by the genetic background, previous stress experiences, social support, and the current state of mood [2]. A negative perception of a stressor gives raise to the stress response (third level) that refers to behavioral, emotional, cognitive, neuroendocrine, and immunological alterations in order to maintain homeostasis [3]. If severity, duration, or frequency of the stress response exceed a critical degree, the associated psychobiological alterations may cause physical damage giving raise to the initiation, acceleration, and exacerbation of various somatic diseases [4].

\section{Crohn's Disease, Ulcerative Colitis, and Indeterminate} Colitis

Three clinical entities of chronic gastrointestinal inflammations, summarized as inflammatory bowel diseases (IBD), are characterized by an unpredictable irregular disease course with active and inactive periods [5]. Most frequent symptoms during the active periods are slimy diarrheas, less often bloody in Crohn's disease (CD) than in ulcerative colitis (UC), and abdominal colic-like pain. Longer episodes of activity may result in disturbed digestion and absorption with subsequent nutritional deficits and weight loss. Extraintestinal dermatologic and ocular symptoms, as well as involvement of articulations, are more frequent in CD than in UC. Typical complications are fistula and stenoses in $\mathrm{CD}$ as well as major bleeding and toxic dilatation of the colon in UC. With increasing duration of the disease, malignancy may occur in both UC and CD.

$\mathrm{CD}$ can affect the whole gastrointestinal tract with discontinuously located lesions (so-called skip lesions) involving all layers as well as the mesenteric lymph nodes [5]. In contrast, UC is limited to mucosa and submucosa and begins in the rectum advancing continuously through the colon and, in some cases, reaching the distal ileum. If CD cannot be differentiated from UC, the condition is called indeterminate colitis, which is the diagnosis in approximately $10 \%$ of IBD cases.

Dietary therapy includes easily digestible food to prevent nutritional deficits [5]. Medication includes 5-aminosalicylates, immune suppressors (azathioprine, 6-mercaptopurine, methotrexate), topic and systemic steroids, and anti-tumor necrosis factor- $\alpha$ agents (infliximab, adalimumab, certolizumab). In case of complications in $\mathrm{CD}$ or nonresponsiveness to treatment in UC, surgery may become a necessary therapeutic option. In CD, surgery must be minimal to avoid a 'short bowel syndrome'.

\section{Stress and IBD}

The etiology of IBD is likely manifold but, as is also true for the involved pathophysiology, has not yet been fully understood [6]. Enquiries among IBD patients, anecdotic case reports, mouse models, as well as clinical retrospective and prospective IBD studies all suggest a relation between stress and the course of IBD. Nevertheless, this relation has neither been proven nor disproved yet, mainly due to the small number of publications on the subject [7]. The focus of this review was to critically discuss prospective studies on the influence of psychological stress on IBD. We particularly aimed to scrutinize the applied methodology in order to devise recommendations for future investigations.

\section{Materials and Methods}

As a first step, prospective studies analyzing the influence of stress on IBD were searched using the PubMed electronic library (fig. 1). The reference lists of the located prospective studies and reviews were examined for additional prospective studies on this topic, but no additional study was found.

As a second step, two of the located prospective studies were excluded: a study on physical stress (cold) was out of the scope of this review [8]. A study published before 1990 failed to provide information on the duration of the follow-up [9].

As a third step, we carefully analyzed the included studies and tabulated the extracted data. Study aims, patient samples, diagnoses, standard treatments, study designs, covariate analyses, and outcomes were compared across studies. We screened publications for data overlap, attentive choice of applied exclusion criteria, reliability of IBD diagnoses at study enrolment, and uniformity of medication between study participants, as well as for changes in medication regimens during study follow-up. We particularly focused on methodological aspects such as sample sizes and characteristics, disease activity at baseline, consideration of the different stress levels (stressor, perception, response), definition of outcome, choice of data collection instruments, data analysis and interpretation, and testing for potential confounders.

Finally, study results were descriptively compared to possibly identify variables, which might help explain the presence or absence of a significant relationship between stress and IBD outcomes. However, because the various studies stated a range of different hypotheses and aims, and applied considerably different procedures, a formal meta-analysis was not feasible.

\section{Results}

\section{Publications and Aims}

We reviewed 20 eligible publications reported between 1990 and 2008 [10-29]. 2 studies were published by Levenstein et al. [20, 22], 2 by Bitton et al. [10, 19], and 2 by Maunder et al. $[12,13]$, each based on different data. Data 


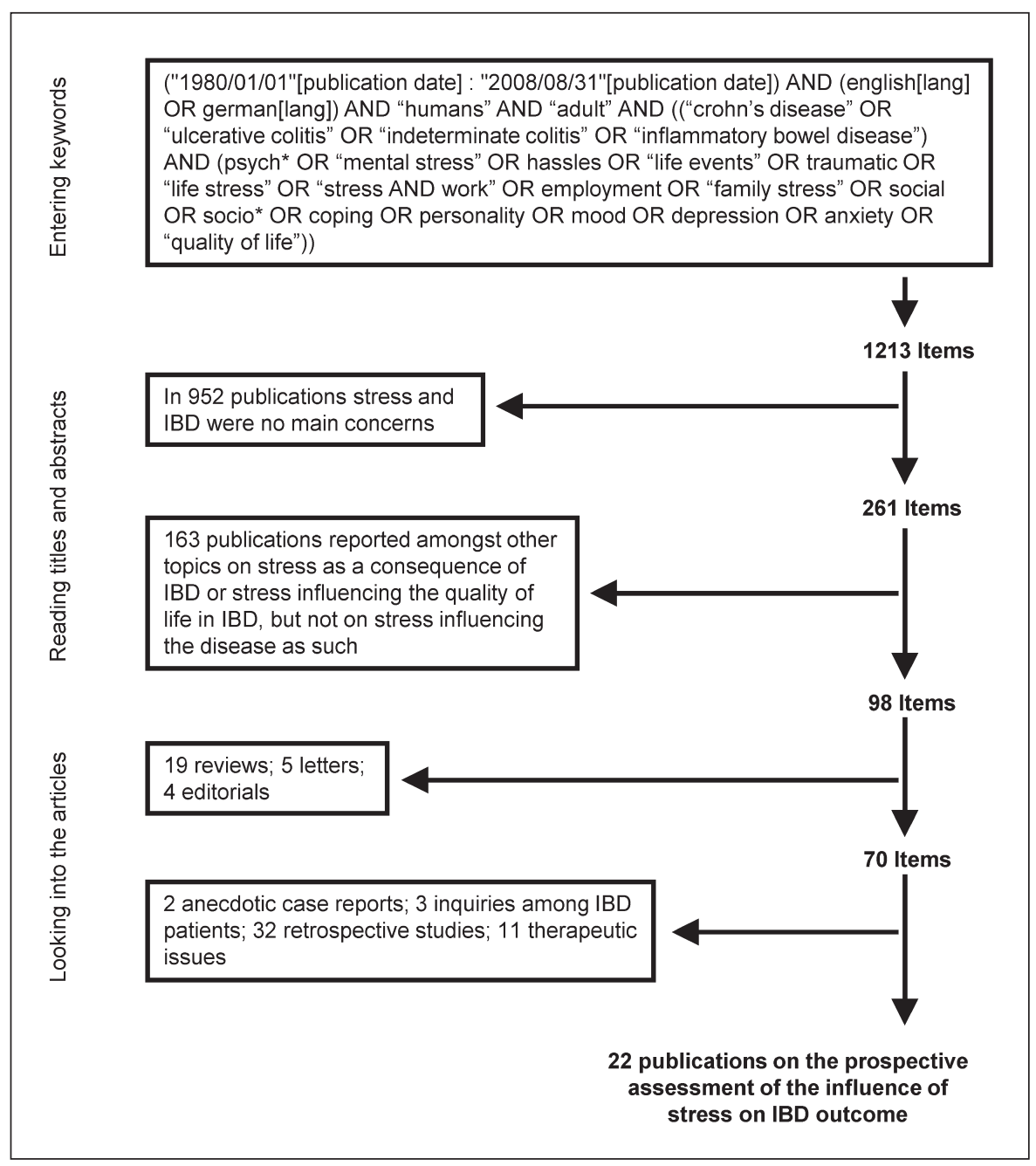

Fig. 1. Literature search.

of the latter 2 studies $[12,13]$, however, showed partial overlap. Duffy et al. $[25,26]$ reported twice on the same data addressing different questions. Mittermaier et al. [18] reported twice on the same data addressing the same question after 1 [24] and 3 years [23] of follow-up performing 5 and 10 longitudinal assessments, respectively. In the following, the 2 publications of Duffy et al. as well as the 2 publications of Mittermaier et al. will be considered as 1 study of the respective group.

In terms of stress, studies aimed to assess minor daily stressors [27], stressful live events [15, 23-25, 28], distress [17], psychosocial stress [21], psychological factors [20, $22]$, depressive mood $[18,28]$, anxiety [18], and major depressive disorder [16]. Outcomes were disease activity [17, $18,20,22]$, frequency of relapses $[15,25]$ and exacerbations $[23,24,28]$, nonresponse to treatment [16], change of symptoms [21], and primary indices [27]. Two studies defined the exact time interval between a stressful event [26] and psychosocial characteristics [19], respectively, and IBD relapse. Two studies examined the effect of seasonal patterns [29] and various biological aspects of the disease in addition to stress [10]. A study on IBD, irritable bowel syndrome, and chronic hepatitis $\mathrm{C}$ investigated the influence of psychological comorbidity on clinical outcome as a first aim and on the response to standard treatment as a second aim [11]. In addition, studies reported on the effects of acute psychological stress on systemic and rectal mucosal inflammatory responses [14], the association between individual differences in autonomic function and disease course [13], and possible differences of psychobiological interactions between perinuclear antineutrophil cytoplasmic antibody (pANCA)-positive and negative UC subjects [12]. 
Table 1. Applied methodologies in the different prospective studies

\begin{tabular}{|c|c|c|c|c|c|c|c|c|c|c|c|c|}
\hline \multirow{2}{*}{$\begin{array}{l}\text { Study } \\
\text { Ref. No. }\end{array}$} & \multicolumn{3}{|c|}{ Patient groups ${ }^{1}$} & \multicolumn{2}{|c|}{$\begin{array}{l}\text { Working } \\
\text { hypotheses }{ }^{2}\end{array}$} & \multicolumn{4}{|c|}{ Criteria included in the definitions ${ }^{3}$} & \multicolumn{3}{|c|}{ Follow-up assessment ${ }^{4}$} \\
\hline & diagnosis & number & activity & focus & outcome & stressor & perception & response & outcome & stress & outcome & time \\
\hline 10 & $\mathrm{CD}$ & $101(60)$ & I & $\mathrm{P}$ & $\mathrm{R}$ & $\mathrm{H}$ & $\mathrm{C}$ & S & $S ; E ; L$ & Q & $\mathrm{P} ; \mathrm{M}$ & $12(5 \times)$ \\
\hline 11 & IBD (54) & $59(?)$ & M (46) & $\mathrm{P}$ & $\mathrm{W}$ & - & M & S & $\mathrm{S}$ & Q & $\mathrm{Q} ; \mathrm{M}$ & $12(5 \times)$ \\
\hline 12 & $\mathrm{UC} \mathrm{S}^{\mathrm{a}}$ & $148(45)$ & $?$ & $\mathrm{P}$ & $\mathrm{W}$ & - & M & - & $S ; E ; M$ & Q & $\mathrm{M} ; \mathrm{E}$ & $7-37(2 \times)$ \\
\hline 13 & UC & $93(48)$ & $\mathrm{M}(71)$ & $\mathrm{R}$ & $\mathrm{W}$ & $\mathrm{H}$ & - & $\mathrm{E}$ & $S$ & $\mathrm{M} ; \mathrm{E}$ & Q & $7-37(2 \times)$ \\
\hline 14 & UC & $25(50)$ & I & $\mathrm{R}$ & $\mathrm{R}$ & $\mathrm{H}$ & M & $\mathrm{E} ; \mathrm{L}$ & $\mathrm{L} ; \mathrm{M}$ & $\mathrm{M} ; \mathrm{E}$ & $\mathrm{M} ; \mathrm{E}$ & $0.03(1 \times)$ \\
\hline 15 & IBD (51) & $155(48)$ & I & S & $\mathrm{R}$ & $\mathrm{E} ; \mathrm{T}$ & - & - & S; E; L & $\mathrm{P}$ & $\mathrm{P} ; \mathrm{M}$ & $11(12 \times)$ \\
\hline 16 & $\mathrm{CD}$ & $100(59)$ & A & $\mathrm{P}$ & $\mathrm{N}$ & - & $C ; M$ & - & $\mathrm{S} ; \mathrm{L}$ & Q & M & $9(2 \times)$ \\
\hline 17 & $\mathrm{CD}$ & $18(67)$ & $?$ & $\mathrm{P}$ & $\mathrm{W}$ & $\mathrm{E}$ & M & - & S; E; L; X & Q & M & $24(8 \times)$ \\
\hline 18 & IBD (78) & $60(62)$ & I & $\mathrm{P}$ & $\mathrm{R}$ & $\mathrm{H}$ & M & - & E; L & $\mathrm{Q}$ & M & $18(7 \times)$ \\
\hline 19 & UC & $60(62)$ & I & S & $\mathrm{R}$ & $\mathrm{E}$ & - & $S$ & M & Q & $\mathrm{P} ; \mathrm{E}$ & $12(13 \times)$ \\
\hline 20 & UC & $62(53)$ & I & S & $\mathrm{R}$ & $\mathrm{E}$ & M & - & $S ; E ; M$ & I & $\mathrm{M} ; \mathrm{E}$ & $45(7 \times)$ \\
\hline 21 & IBD (54) & $11(36)$ & A & S & $\mathrm{W}$ & $\mathrm{H}$ & $C ; M$ & - & S & $\mathrm{D}$ & $\mathrm{D}$ & $12(13 \times)$ \\
\hline 22 & UC & $76(46)$ & I & S & $\mathrm{R}$ & $\mathrm{E}$ & $\mathrm{M}$ & - & M & I & $\mathrm{E}$ & $0.2(1 \times)$ \\
\hline 23,24 & $\mathrm{CD} / \mathrm{UC}^{\mathrm{b}}$ & $57 / 51(56 / 43)$ & A & S & $\mathrm{W}$ & $\mathrm{E} ; \mathrm{T}$ & M & - & S & $\mathrm{Q}$ & Q & $36(10 \times)$ \\
\hline 25,26 & IBD (60) & $124(47)$ & M (65) & $S$ & $\mathrm{~W}$ & $\mathrm{E} ; \mathrm{T}$ & - & - & $\mathrm{E} ; \mathrm{L}$ & $\mathrm{I} ;(\mathrm{P})$ & $\mathrm{M} ;(\mathrm{P})$ & $6(7 \times)$ \\
\hline 27 & $\mathrm{CD}$ & $10(60)$ & $?$ & S & $\mathrm{W}$ & $\mathrm{H}$ & - & - & $S$ & P; Q; D & $\mathrm{D}$ & $1(5 \times)$ \\
\hline 28 & IBD (75) & $32(56)$ & A & S & $\mathrm{W}$ & $\mathrm{E} ; \mathrm{T}$ & M & - & all criteria & Q & Q; M; (E) & $24(25 \times)$ \\
\hline 29 & UC & $92(46)$ & I & S & $\mathrm{R}$ & $\mathrm{E}$ & M & - & M & Q & $\mathrm{D} ; \mathrm{P} ; \mathrm{E}$ & $48(5 \times)$ \\
\hline
\end{tabular}

${ }^{1}$ Diagnosis: IBD $\neq$ distinction (parentheses: $C D$ percentage); $S=$ subtypes. Number: exact number (parentheses: percentage of females). Activity: $\mathrm{I}=$ inactive; $\mathrm{M}=$ mixed (parentheses: inactive percentage); $\mathrm{A}=$ active.

${ }^{2}$ Focus $^{\mathrm{c}}: \mathrm{P}=$ perception; $\mathrm{R}=$ response; $\mathrm{S}=$ stressor. Outcome: $\mathrm{R}=$ relapse; $\mathrm{W}=$ worsening; $\mathrm{N}=$ nonresponse to therapy.

${ }^{3}$ Stressor: $\mathrm{H}=$ hassles; $\mathrm{E}=$ events; $\mathrm{T}=$ traumata. Perception: $\mathrm{C}=$ coping strategies and personality; $\mathrm{M}=$ anxious/depressed mood. Response: $\mathrm{S}=$ symptoms; $\mathrm{E}=$ clinical exam; $\mathrm{L}=$ laboratory. Outcome: $\mathrm{S}=$ symptoms; $\mathrm{E}=$ clinical exam; $\mathrm{L}=$ laboratory; $\mathrm{M}=$ mucosa; $\mathrm{X}=\mathrm{X}$-ray.

${ }^{4}$ Stress: $\mathrm{Q}=$ questionnaires; $\mathrm{M}=$ medical visit; $\mathrm{E}=\operatorname{experimental} ; \mathrm{P}=$ phone; $\mathrm{I}=$ interview; $\mathrm{D}=$ diaries; $(\mathrm{l}$ = irregular use. Outcome: $\mathrm{P}=$ phone;
$\mathrm{M}=$ medical visit; $\mathrm{Q}=$ questionnaires; $\mathrm{E}=$ endoscopy; $\mathrm{D}=$ diaries. Time: follow-up period in months (parentheses: number of regularly scheduled assessments).

a 74 pANCA-positive (32\% females) and 74 pANCA-negative (58\% females) subtypes.

${ }^{\mathrm{b}}$ Separate assessment of CD and UC.

' 'Focus perception' needs search for characteristics that may negatively influence the perception, 'focus response' needs substantial features.

\section{Study Participants}

Table 1 on applied methodologies shows that sample sizes ranged between 10 and 155 patients. Table 2 on covariates and exclusion criteria shows that the latter were defined in 14 studies. Two studies included a control sample. One was part of a clinical study with experimental character and is detailed below [14]. The other was set up with 60 surgical patients ( $48 \%$ females; mean age 29 years) having experienced minor injuries [23, 24]. Except in a few studies $[11,21,23,24,27]$ investigators unequivocally provided the information that the diagnosis of IBD was based on standard clinical, endoscopic, histological, and radiological criteria.

\section{Standard Treatments}

In 6 of 8 studies providing the information, the proportions of patients taking 5-aminosalicylates and im- mune suppressors at study entry ranged between 44 and 81 and between 3 and $46 \%$, respectively $[10,13-15,17,18]$. In 3 of these 6 studies, steroids were allowed with proportions of patients taking steroids ranging between 11 and $39 \%[13,17,18]$. Except one study on the outcome of treatment with infliximab, which showed a repartition of $9 \%$ patients taking 5 -aminosalicylates, $81 \%$ taking immune suppressors, and $9 \%$ taking steroids [16], none was on anti-tumor necrosis factor- $\alpha$ agents. One study precisely stated that all patients were taking 2-4 g of maintenance sulfasalazine or $800-1,600 \mathrm{mg}$ of delayed-release mesalazine daily but no other medication targeting IBD [29].

Only 1 study reported to have provided supportive therapy comprising psychotherapeutic tools like relaxation training in addition to usual clinical therapy [23, 24]. In dietary terms, no information was given about the substitution of important nutritional elements and avoid- 
Table 2. Covariates and exclusion criteria in the different prospective studies

\begin{tabular}{|c|c|c|c|c|c|c|c|c|c|}
\hline \multirow{2}{*}{$\begin{array}{l}\text { Study } \\
\text { Ref. No. }\end{array}$} & \multicolumn{3}{|c|}{ Main characteristics (total groups) ${ }^{1}$} & \multicolumn{2}{|c|}{ Current medication ${ }^{2}$} & \multicolumn{4}{|l|}{ History $^{3}$} \\
\hline & age & sex & duration & medication & changes & evolution & comorbidity & surgery & general \\
\hline 10 & $34(13)$ & $60: 41$ & $90(82)$ & $S ; M ; O ; \mathrm{N} ; \mathrm{I}$ & yes & $\underline{B} ; E ; \underline{A}$ & $\operatorname{Pr}$ & $B ; S$ & S \\
\hline 11 & - & - & - & - & no & - & No & - & - \\
\hline 12 & $44(12)$ & $67: 81$ & $180(120)$ & $\mathrm{S} ; \mathrm{O}$ & no & $\mathrm{E}$ & $C$ & $C$ & S \\
\hline 13 & $44(11)$ & $45: 48$ & $192(120)$ & $\mathrm{N} ; \mathrm{S} ; \mathrm{I} ; \mathrm{O}$ & no & $\mathrm{E}$ & C & $C$ & - \\
\hline 14 & 44 & $12: 13$ & - & $S$ & no & - & No & - & - \\
\hline 15 & $37(13)$ & $74: 81$ & $73(67)$ & $S ; M ; O ; \mathrm{N} ; \mathrm{I}$ & yes & B; E; A; EI & - & $C ; \mathrm{B} ; \mathrm{S}$ & S \\
\hline 16 & $34(11)$ & $59: 41$ & 120 & N; S; I; O & no & $\mathrm{B} ; \mathrm{E} ; \mathrm{A}$ & No & $B ; S ; \mathrm{C} ; \mathrm{O}$ & $S^{c}$ \\
\hline 17 & 31 & $12: 6$ & 84 & N; S; I; M; O & no & $B^{\mathrm{a}}$ & $P s$ & $B ; S ; C$ & $\mathrm{~S} ; \mathrm{A} ; \mathrm{F} ; \mathrm{E}$ \\
\hline 18 & 31 & $37: 23$ & 60 & N; S; I; O & $\mathrm{R}$ & $\mathrm{E} ; \mathrm{A}$ & Ps & $S$ & $\mathrm{~S} ; \mathrm{E}^{\mathrm{c}}$ \\
\hline 19 & $39(9)$ & $37: 23$ & - & $S$ & yes & A & c & - & c \\
\hline 20 & $39(13)$ & $29: 33$ & $78(72)$ & $S ; \mathrm{N} ; \mathrm{O}$ & yes & $\mathrm{E} ; \mathrm{A}$ & No & - & S; I; F \\
\hline 21 & $47(-)$ & $4: 7$ & $108(-)$ & - & no & - & No & - & - \\
\hline 22 & $39(14)$ & $21: 46$ & $73(66)$ & $S ; I ; M ; O$ & no & $\mathrm{E}$ & - & No & $S ; E^{c}$ \\
\hline 23,24 & $29(-)$ & $54: 54$ & - & - & no & - & No & - & - \\
\hline 25,26 & $40(13)$ & $58: 66$ & - & o & no & $\mathrm{E}^{\mathrm{b}}$ & $P s ; P r$ & $\mathrm{~b} ; \mathrm{s} ; \mathrm{c}$ & $S ; a ; F ; e^{c}$ \\
\hline 27 & $41(11)$ & $6: 4$ & $136(112)$ & - & no & - & No & S & - \\
\hline 28 & $38(13)$ & $18: 14$ & - & - & no & - & - & - & - \\
\hline 29 & - & $42: 50$ & - & $S ; \mathrm{N} ; \mathrm{O}$ & yes; $\underline{D}$ & $\mathrm{E} ; \mathrm{A}$ & No & - & $\underline{I}^{c}$ \\
\hline
\end{tabular}

${ }^{1}$ Age: mean in years (parentheses: standard deviation); italics = median. Sex: absolute numbers (F:M). Duration (of the disease): mean in months (parentheses: standard deviation; italics $=$ median).

${ }^{2}$ Medication: $\mathrm{S}=$ steroids; $\mathrm{M}=$ anti-tumor necrosis factor- $\alpha$ agents; $\mathrm{O}=$ other $^{\mathrm{d}} ; \mathrm{N}=$ non steroidal anti-inflammatory drugs; $\mathrm{I}=$ immune suppressors $^{\mathrm{e}}$. Changes (in the regimen during followup): $\mathrm{R}=$ considered as a relapse; $\mathrm{D}=$ dietary changes.

${ }^{3}$ Evolution (before enrolment): $\mathrm{B}=$ behavior ${ }^{\mathrm{f}} ; \mathrm{E}=$ extent; $\mathrm{A}=$ activity; $\mathrm{EI}=$ extraintestinal. Comorbidity: $\mathrm{Pr}=$ pregnancy; $\mathrm{C}=$ cardiovascular; Ps = psychiatric. Surgery: $\mathrm{B}=$ short bowel syndrome; $\mathrm{S}=$ stoma; $\mathrm{C}=$ colectomy; $\mathrm{O}=$ other. General: $\mathrm{S}=$ smoking; $\mathrm{A}=$ alcohol; $\mathrm{F}=$ family and race; $\mathrm{E}=$ socioeconomic; $\mathrm{I}=$ infections.
Italics represent exclusion criteria. Underlining represents test variables as parts of the study aims. Lower case letters indicate variables only mentioned in the first $(o, e)$ or in the second $(b, s$, c, a) publication. - = No information provided.

a Exclusion of fistulizing CD.

${ }^{\mathrm{b}}$ Exclusion of current ischemic colitis and malignancy.

${ }^{c}$ Basal plasmocytosis [19], residence [18], marital status [16, 18, $22,25,26]$, seasonal patterns $[22,29]$.

d Analgesics [16, 25], antidepressants [12, 13, 16-18], sedatives $[12,13,16]$, hypnotics $[16,18]$, oral contraceptives $[10,13,18]$, antibiotics [10, 15-17], all non-IBD medicaments [22].

${ }^{\mathrm{e}}$ Azathioprine, 6-mercaptopurine, methotrexate.

${ }^{\mathrm{f}}$ Fistulizing, inflammatory, or stricturing. ance of substances such as lactose that might affect digestion.

\section{Study Designs and Follow-Up}

Table 3 on conceptualizations of relations between stress and outcome shows that in 16 of 18 studies, a total of 26 different psychometric instruments were used as the main and, in most cases, as the only tool for the evaluation and definition of 'stress'. None of these 26 psychometric instruments was used in more than 3 studies. Eleven of the 16 studies used self-report instruments and 5 studies collected psychometric data by either phone or personal interviews (table 1). Two studies did not use psychometric instruments as main tools, but applied a stan- dardized experimental stressor $[13,14]$. In the first study, participants had to recall a recent stressful situation, while subjective stress was measured on a visual analogue scale [13]. In the second study, the test group underwent an IQ test under time pressure and sensory distraction, while the control subjects (10 UC patients; 7 females; median age 52 years) listened to relaxing music of their choice [14].

Three studies used momentary outcome assessment in addition to the regularly scheduled follow-up visits $[10$, 19, 29]. In two of these studies the patients were advised to inform the research coordinator when they developed symptoms $[10,19]$, whereas in the third they were additionally asked to complete a symptom diary for a more 
Table 3. Conceptualizations of relations between stress and outcome

\begin{tabular}{|c|c|c|c|}
\hline $\begin{array}{l}\text { Study } \\
\text { Ref. } \\
\text { No. }\end{array}$ & Stress conceptualizations & Outcome conceptualizations & $\begin{array}{l}\text { Relation } \\
\text { reported }\end{array}$ \\
\hline 10 & $\begin{array}{l}\text { Hassles Scale; Perceived Stress Scale; Coping Inventory for Stressful } \\
\text { Situations; Symptom Checklist-90R; Global Severity Index }{ }^{b}\end{array}$ & CD Activity Index $\geq 150$ with increase of $\geq 70 \mathrm{P}^{\mathrm{a}}$ & $Y e s^{* *}$ \\
\hline 11 & $\begin{array}{l}\text { Hospital Anxiety and Depression Scale } \geq 7 \text { Pa; Symptom } \\
\text { Checklist-90R; Short Form } 12 \text { Health Survey }\end{array}$ & $\begin{array}{l}\text { CD Activity Index } \geq 150 \text {; Simple Clinical Colitis Activity } \\
\text { Index } \geq 3^{\text {a }}\end{array}$ & No \\
\hline 12 & $\begin{array}{l}\text { Center for Epidemiologic Studies Depression Scale } 616 \text { Pa ; Ilness } \\
\text { Behaviour Questionnaire }\end{array}$ & St. Mark's Index ${ }^{\mathrm{b}}$ (clinical and endoscopic activity index) & $* * * * * *$ \\
\hline 13 & $\begin{array}{l}\text { No increase }{ }^{\mathrm{a}} \text { of the high frequency heart rate variability } 5 \mathrm{~min} \\
\text { after stress recall as a function of an altered stress response }\end{array}$ & Self-report items of the St. Mark's Index $\geq 3^{\text {a }}$ & Yes $^{* *}$ \\
\hline 14 & All participants who were in the intervention group & $\begin{array}{l}\text { Momentary systemic (IL- } 6 \text {, TNF- } \alpha \text {, NK cells, platelet } \\
\text { activation, PLA formation) and rectal mucosal inflammatory } \\
\text { response }^{\mathrm{a}}\end{array}$ & Yes $^{* *}$ \\
\hline 15 & $\begin{array}{l}\text { Modified Spanish version of the Holmes and Rahe Social } \\
\text { Readjustment Rating Scale }^{\mathrm{b}}\end{array}$ & CD Activity Index $\geq 175$; UC Truelove-Witts Index $\geq 8^{a}$ & No \\
\hline 16 & $\begin{array}{l}\text { Patient Health Questionnaire; Anxiety Subscale of the Hospital } \\
\text { Anxiety and Depression Scale; number of sleep hours; Toronto } \\
\text { Alexithymia Scale; Social Support List Interactions }{ }^{\mathrm{b}}\end{array}$ & $\begin{array}{l}\text { CD Activity Index Score decrease of } \geq 70 \text { P means response, } \\
\text { total score of }<150 \text { P means remission; retreatment need } \\
\text { means relapse } \mathrm{a}^{\mathrm{a}}\end{array}$ & $Y e s^{* *}$ \\
\hline 17 & $\begin{array}{l}\text { Beck Depression Inventory; Beck Anxiety Inventory; Beck } \\
\text { Hopelessness Scale; Holmes Recent Life Changes }{ }^{\mathrm{b}}\end{array}$ & Increase of the CD Activity Index ${ }^{a}$ & $Y e s^{* *}$ \\
\hline 18 & $\begin{array}{l}\text { Beck Depression Inventory } \geq 13 P^{\text {a }} \text {; Spielberger State-Trait Anxiety } \\
\text { Inventory; Perceived Stress Questionnaire }\end{array}$ & $\begin{array}{l}\text { CD Activity Index } \geq 150 \mathrm{P} \text { or increase of } \geq 70 \mathrm{P}^{\mathrm{a}} \\
\text { Colitis Activity Index } \geq 6 \mathrm{P}^{\mathrm{a}}\end{array}$ & $Y e s^{* *}$ \\
\hline 19 & $\begin{array}{l}\text { Psychiatric Epidemiology Research Life Events Scale; Perceived } \\
\text { Stress Scale; Symptom Checklist-90R } \mathrm{R}^{\mathrm{b}}\end{array}$ & $\begin{array}{l}\text { Rectosigmoidal erythema with loss of vascular pattern plus } \\
\text { contact bleeding, spontaneous bleeding, or obvious } \\
\text { ulceration }^{\text {a }}\end{array}$ & $Y e s^{* *}$ \\
\hline 20 & $\begin{array}{l}\text { Comparison of the upper with the middle and the lower tertile of } \\
\text { the Perceived Stress Questionnaire; Paykel Life Experiences } \\
\text { Interview; Center for Epidemiologic Studies Depression Scale }\end{array}$ & $\begin{array}{l}\text { Hematochezia, passage of mucus, liquid stools, tenesmus, } \\
\text { and increased number of bowel movements in addition to } \\
\text { mucosal inflammatory activity or intensified need of therapy }\end{array}$ & Yes** \\
\hline 21 & Psychosocial Stress Diary ${ }^{\mathrm{b}}$ & IBD Symptom Diary Score & Yes** \\
\hline 22 & $\begin{array}{l}\text { Paykel Life Experiences Interview; Spielberger State-Trait Anxiety } \\
\text { Inventory; Center for Epidemiologic Studies Depression Scale; } \\
\text { Perceived Stress Questionnaire }\end{array}$ & $\begin{array}{l}\text { Inflammation criteria on the rectal mucosa such as erythema, } \\
\text { edema, friability, or bleeding }{ }^{\mathrm{a}}\end{array}$ & $Y e s^{* *}$ \\
\hline 23,24 & $\begin{array}{l}\text { Modified German version of the Holmes and Rahe Social } \\
\text { Readjustment Rating Scale; self-developed questionnaire for } \\
\text { feelings and events } \mathrm{s}^{\mathrm{b}}\end{array}$ & $\begin{array}{l}\text { Increase of } \geq 30 \mathrm{P}^{\mathrm{a}} \text { in a UC compatible abbreviated version } \\
\text { of the CD Activity Index that includes only symptoms }\end{array}$ & $\begin{array}{l}\text { No for CD } \\
\text { No for UC }\end{array}$ \\
\hline 25,26 & Schedule of Recent Experiences Score above the median ${ }^{a}$ & UC-compatible modification of the CD Activity Index $\geq 150^{a}$ & Yes** \\
\hline 27 & Daily Stress Inventory; Life Experiences Survey ${ }^{\mathrm{b}}$ & Diary of CD symptoms & $Y e s^{* *}$ \\
\hline 28 & $\begin{array}{l}\text { Holmes and Rahe Social Readjustment Rating Scale; increase of } \\
\geq 4 \text { P of } \geq 2 \text { Beck Depression Inventory Scores }{ }^{\mathrm{a}} \text { excluding IBD } \\
\text { symptoms }\end{array}$ & $\begin{array}{l}\text { Inventory of Intestinal Symptoms; Clinical Rating Score }{ }^{\mathrm{a}} \\
\text { (endoscopic examination was only performed 'when } \\
\text { appropriate') }\end{array}$ & No \\
\hline 29 & $\begin{array}{l}\text { Paykel Life Events Scale; Hospital Anxiety and Depression Scale } \\
\geq 8 \mathrm{P}^{\mathrm{a}}\end{array}$ & Macroscopic worsening of the mucosal inflammation & No \\
\hline \multicolumn{4}{|c|}{$\begin{array}{l}\text { Only the scales in italics were reported to significantly predict outcomes. }{ }^{* *} \mathrm{p}<0.05 . \mathrm{P}=\text { Scorepoints; }{ }^{* *} \text { Yes for pANCA-negative UC subjects, no } \\
\text { for pANCA-positive UC subjects. } \\
{ }^{\text {a }} \text { Dichotomized (active/inactive or worse/not worse). } \\
{ }^{b} \text { Conceptualized as a continuous variable. }\end{array}$} \\
\hline
\end{tabular}


attentive self-observation [29]. Further studies performed regular control visits by phone to determine the necessity of a subsequent medical visit [15], completed clinical scores using questionnaires [28] and missing information by phone calls $[25,26]$, or reminded participants by phone when questionnaires were returned incompletely or too late [19].

\section{Covariates}

Most studies collected data on predictors for statistical analyses, but only few included medication changes or dosage alterations during follow-up (table 2).

\section{Comparison of the Study Results}

Thirteen of 18 prospective studies found statistically significant associations between stress and IBD outcome (table 3). Eight studies directly focused on stress-disease relations [16-18, 20-22, 25, 27], 1 in a first publication commented on the time interval between stress and outcome [19], 1 examined additional clinical and biological aspects [10], 2 applied standardized experimental stress $[13,14]$, and 1 differentiated UC patients by pANCA status [12]. Fistulizing disease and elevated C-reactive protein [10] as well as the season between August and January [29] were reported as predictors of relapse.

In terms of diagnosis, significant results were found in 4 of 5 CD samples [10,16,17,27], in 6 of 8 UC samples $[12-14,19,20,22]$, and in 3 of 6 mixed IBD samples [18, $21,25,26]$. When comparing the baseline disease activity of the samples, 6 of 8 with inactive [10,14, 18-20,22], 2 of 5 with active [16, 21], and 1 of 3 with mixed activity [21] showed significant associations between stress and IBD outcomes.

All 4 studies allowing for steroids $[13,16-18]$ and 2 of the 4 studies in which steroids were not allowed [10, 14, $15,29]$ reported significant results.

\section{Discussion}

\section{General Interpretation of the Results}

There are many possibilities to measure stress, and which one is most effective is an unresolved issue. The importance attributed to the three levels of the stress cascade, as well as to their corresponding categories, was quite different among the researchers. Daily hassles such as getting stuck in traffic are qualitatively and quantitatively different from major events with possible long impacts such as a divorce or a dramatic car accident. Since those different categories are not at scale (how many times more stressful is a major event than a daily hassle?), assessing all of them and adding them up to a total stressor score leads to an additional difficulty: the attribution of score points is arbitrary. These issues are some of the main reasons for why so many stress scales were used in the reviewed studies. The studies measuring the second level of the stress cascade (perception) opted for psychological symptoms rather than for coping strategies, the symptoms of choice being depression and anxiety. However, researchers assessed the mere states of mood but did not make a firm diagnosis of a psychiatric disorder using a clinical interview. Focusing on the third level of the stress cascade requires experimental stress provocation, which is not purely clinical, even when performed in IBD patients, or constant assessment of physiological equivalents such as an increase in pulse and perspiration.

It seemed easier to define the outcome, which was regularly done in relation to baseline disease activity. However, the accuracy of the assessments differed strongly. Not surprisingly, onset of the disease was not taken as outcome in any of the prospective studies. Such a design would require the observation of very large numbers of healthy subjects during very long periods. Among the retrospective studies addressing this important question, one with prospective characteristics used national registers to compare the onset rates of IBD between parents who had lost a child to those who had not [30]. It was found that the onset rates were not significantly more frequent in the parents who had lost a child.

In comparison with studies which were performed before 1990 [31, 32], the providing of essential information including on age, sex, disease activity, and standard treatment as well as the reliability of the diagnoses have considerably improved.

We did not find apparent evidence for any correlation between significant and nonsignificant results on the one hand and issues related to patient samples, use of psychometric instruments, exactitude of outcome assessments, and other methodological issues on the other. However, this could be a consequence of the disparity of the methodological approaches which, moreover, is highlighted by the fact that virtually no study set out to replicate previous findings with similar methods.

\section{Not All Procedures Are Mere Matters of Choice}

Some decisions depend on circumstances limited by the study resources, particularly the sample size and follow-up period. The larger the sample, the more accurately can a study control for confounders and account for variability in terms of age, sex, and standard medication 
Fig. 2. The area under the curve: groups and comparisons. It is not sufficient to assess the baseline activity, which is only one point on the curve. Ideally, the previous 2 years should at least be considered. Moreover, previous activity, stress, and outcome should be calculated versus time [35]. This allows a direct comparison between different time intervals of the follow-up period within patients with similar disease behavior.

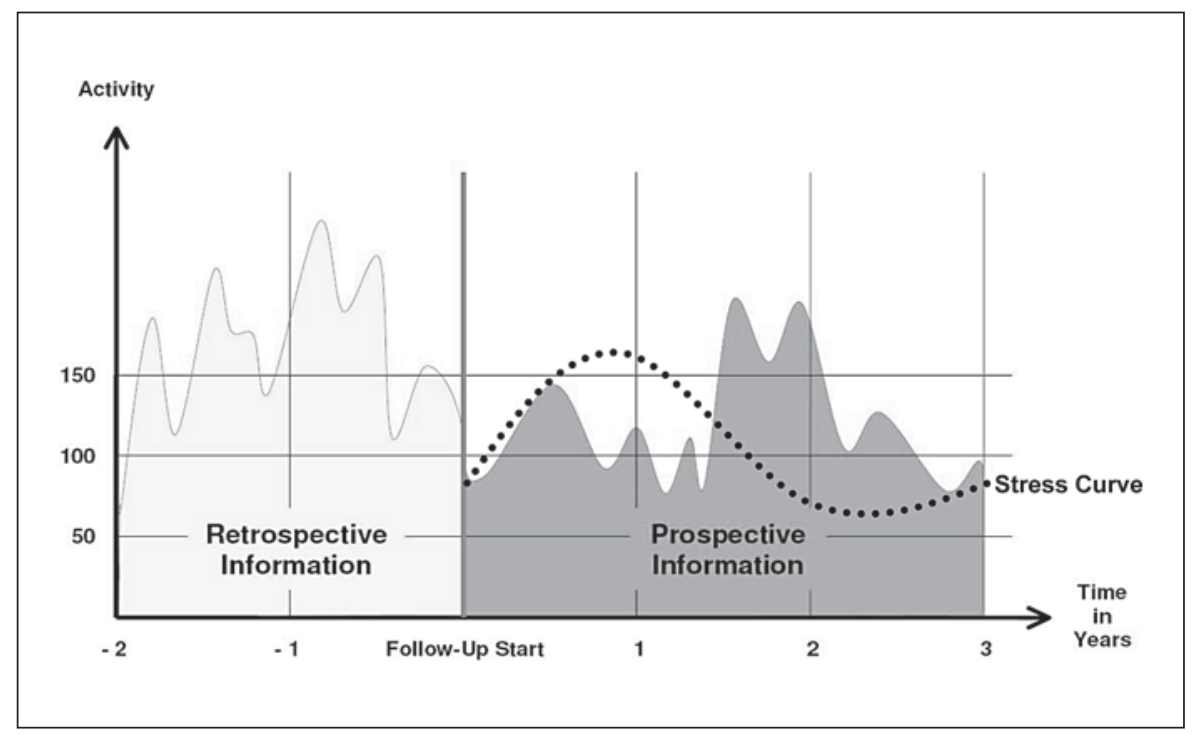

[33]. Therefore, studies able to include many patients may rely on multivariate models to test for explained variation, whereas studies with fewer resources must define inclusion and exclusion criteria very carefully beforehand. However, no study is exempted from collecting data on predictors as well as demographic information in order to be able to compare with the outcome.

Much financial and staff support would be needed to repeatedly assess endoscopic and clinical activity indices in large samples over long periods. Hence, concerned studies must look for more convenient methods of outcome assessments, which are naturally less sensitive and specific. Studies with small samples can obtain more accurate outcome data by more frequent and more exact assessments, but they must consider that repeated and invasive sampling of data will also be more stressful to the patients. Laboratory serum and fecal activity markers of inflammation in a broad sense may be an additional option [34].

The more frequently changes in life happen during the follow-up period, the more prospective data can be recorded. Hassles occur more often than life events and are thus more likely to be observed. In addition, recovery from hassles and minor life events will be quicker than recovery from a traumatic event. The latter will probably take longer than the follow-up itself, and so there is little difference whether this event is assessed prospectively or retrospectively. Likewise, when analyzing characteristics influencing stress perception, personality and coping behavior being trait characteristics of a person might have less prospective value than characteristics which change during follow-up like depressed mood. Unless experimental stress is used, we therefore suggest that studies with a follow-up of up to 1 year should focus on hassles, while studies with longer periods can also focus on major life events.

\section{Further Possibilities for More Effective Research}

All variables mentioned in the 20 publications plus regular physical activity and anthropomorphic measures (including body mass index) should be considered. These variables $(\mathrm{n} \approx 30)$ are either of general clinical importance, well-known IBD risk factors, or recently identified relapse predictors $[10,19,29]$, although not necessarily confounders.

To avoid dilution effects, IBD cohort samples should be divided into groups with the same diagnosis, or, depending on the sample size, restricted to one diagnosis [7]. It is intriguing that none of the reviewed studies commented on indeterminate colitis, although this entity is diagnosed in 10\% of IBD. CD must be divided into groups of inflammatory, stricturing, and fistulizing behavior because these types show different disease courses $[5,10]$. Moreover, investigations on UC might profit from patient assignment into pANCA-positive and negative groups because stress appeared to particularly predict adverse outcome in the pANCA-negative UC patients [12]. As recently shown, the categorization of patients by their autonomic stress response, as measured by opposite changes in heart rate variability during acute psychological 
Table 4. Recommendations and their accomplishment in the analyzed studies

\begin{tabular}{llllllllllllllllllllll}
\hline Study Ref. No. & 10 & 11 & 12 & 13 & 14 & 15 & 16 & 17 & 18 & 19 & 20 & 21 & 22 & $\begin{array}{l}23, \\
24\end{array}$ & $\begin{array}{l}25, \\
26\end{array}$ & & & & & &
\end{tabular}

Plus points

Focus on daily hassles ${ }^{\mathrm{a}}$

Potential confounders ${ }^{\mathrm{b}}$

All important variables

Diagnoses $^{c}$

Subdiagnoses ${ }^{\mathrm{c}}$

Disease activity

Area under the curve disease activity

Personality and coping ${ }^{c}$

HF HR variability ${ }^{c}$

Gradual stress

Area under the curve gradual stress

Gradual outcome

Area under the curve gradual outcome

Appropriate $\alpha$-adjustment

Relapse treatment ${ }^{\mathrm{d}}$

Use of symptom diaries

$\begin{array}{llllllllllllllllll}0 & 0 & 0 & 1 & 1 & 0 & 0 & 0 & 0 & 0 & 1 & 1 & 0 & 1 & 0 & 1 & 1 & 1 \\ 1 & 0 & 1 / 2 & 1 / 2 & 1 / 2 & 1 & 1 / 2 & 1 & 1 / 2 & 1 & 1 / 2 & 0 & 1 & 0 & 1 / 2 & 1 / 2 & 0 & 1 / 2 \\ 0 & 0 & 0 & 0 & 0 & 0 & 0 & 0 & 0 & 0 & 0 & 0 & 0 & 0 & 0 & 0 & 0 & 0 \\ 1 & 0 & 1 & 1 & 1 & 0 & 1 & 1 & 0 & 1 & 1 & 0 & 1 & 1 & 0 & 1 & 0 & 1 \\ 1 / 2 & 0 & 1 & 0 & 0 & 0 & 1 / 2 & 1 / 2 & 0 & 0 & 0 & 0 & 0 & 0 & 1 / 2 & 0 & 0 & 0 \\ 1 & 0 & 0 & 0 & 1 & 1 & 1 & 0 & 1 & 1 & 1 & 1 & 1 & 1 & 0 & 0 & 1 & 1 \\ 1 / 2 & 0 & 0 & 0 & 0 & 1 / 2 & 1 / 2 & 0 & 1 / 2 & 1 / 2 & 1 / 2 & 0 & 0 & 0 & 0 & 0 & 0 & 1 / 2 \\ 1 / 2 & 0 & 0 & 0 & 0 & 0 & 1 / 2 & 0 & 0 & 0 & 0 & 1 / 2 & 0 & 0 & 0 & 0 & 0 & 0 \\ 0 & 0 & 0 & 1 & 0 & 0 & 0 & 0 & 0 & 0 & 0 & 0 & 0 & 0 & 0 & 0 & 0 & 0 \\ 1 & 0 & 0 & 0 & 1 / 2 & 1 & 1 & 1 & 0 & 1 & 0 & 1 & 1 & 1 & 0 & 1 & 0 & 0\end{array}$

Minus points

No age information

No sex information

No diagnosis reliability

No activity information

No treatment information ${ }^{\mathrm{e}}$

Total score (of -5 to 16 )

$\begin{array}{llll}0 & 0 & 0 & 0 \\ 0 & 0 & 1 & 0\end{array}$

$\begin{array}{lll}0 & 0 & 0 \\ 0 & 0 & 0\end{array}$

$\begin{array}{ll}0 & 0 \\ 0 & 0\end{array}$

$\begin{array}{lllllllll}0 & 0 & 0 & 0 & 0 & 0 & 0 & 0 & 0 \\ 0 & 0 & 0 & 0 & 0 & 0 & 0 & 0 & 0\end{array}$

Positive results

$\begin{array}{llllllllllllllllll}0 & 0 & 0 & 0 & 0 & 0 & 0 & 0 & 0 & 0 & 0 & 0 & 0 & 0 & 0 & 0 & 0 & 0 \\ 0 & 0 & 0 & 1 & 1 & 1 & 0 & 0 & 0 & 1 & 0 & 1 & 1 & 0 & 1 & 0 & 0 & 0 \\ 1 & 0 & 0 & 0 & 0 & 1 & 1 & 0 & 1 & 1 & 0 & 0 & 1 & 0 & 0 & 0 & 0 & 0 \\ 0 & 0 & 0 & 0 & 0 & 0 & 0 & 0 & 0 & 0 & 0 & 1 & 0 & 0 & 0 & 1 & 0 & 1\end{array}$

Yes $=1$ point; partly $=1 / 2$ point; $\mathrm{No}=0$ point

$\mathrm{HF} \mathrm{HR}=$ High-frequency heart rate.

${ }^{a}$ Or life events if follow-up $>1$ year.

${ }^{\mathrm{b}}$ For regression analysis with $\mathrm{n}=30$ variables a sample size of at least 300 patients is needed [33], so that all reviewed sample sizes were considered small: 1 point $=$ careful setting of exclusion criteria.
${ }^{c}$ Uniformity either achieved at inclusion or by subsequent division into groups.

d Standardized treatment of relapses or computing time to relapse $=1$ point.

${ }^{\mathrm{e}}$ Exclusion criteria concerning medication but no information on the repartition $=-1 / 2$ point. stress and recovery, seems also a fruitful endeavor for future studies [13].

If a study aims to analyze all of the proposed subpopulations, a huge sample size would be required. Suppose that the main independent variable is a questionnaire score ranging from 1 (no stress) to 100 (maximum stress) that has a standard deviation of 25 from the mean. A research group decides that the odds ratio for new extraintestinal manifestations per unit should be at least $2 \%$ to be clinically relevant. To detect that odds ratio at a $5 \%$ significance level with a power of $90 \%, 300$ patients have to be observed until at least $54(18 \%)$ show extraintestinal manifestations. The study that performed best with respect to this calculation example included $148 \mathrm{UC}$ patients, half of them being ANCA positive [12]. Since the number of required patients increases in proportion to the number of subpopulations to be analyzed, most studies will probably have to focus on one entity in order to remain feasible in terms of available funding resources.

Further recommendations include more reliable conceptualization not only of stress, but also of disease activity indices as gradual variables (fig. 2), $\alpha$-adjustment 
of $\mathrm{p}$ values in case of multiple comparisons, uniformity in the treatment of relapses during the observation period, and complementary use of symptom diaries for nonscheduled momentary self-assessment of stress and outcomes.

\section{Conclusions}

We summarized the above recommendations and, if they were considered, assigned score points (table 4). No study scored high and no relation was revealed between score points and the significance of published results. There is still much potential for improvement of study designs probing for an effect of psychological stress on IBD since previously applied methodologies influenced the validity of the results rather than the results as such.

\section{Acknowledgment}

This work was supported by grant 33CSC0-108792 from the Swiss National Science Foundation to R.v.K. and S.B. (Mental Health Core Project of the SIBDCS).

\section{References}

1 Lazarus RS, Folkman S: Stress, Appraisal, 11 Mikocka-Walus AA, Turnbull DA, Mouldand Coping. New York, Springer, 1984.

$\checkmark 2$ Adler N, Matthews K: Health psychology: why do some people get sick and some stay well? Annu Rev Psychol 1994;45:229-259.

3 Chrousos GP, Gold PW: The concepts of stress and stress system disorders. Overview of physical and behavioral homeostasis. JAMA 1992;267:1244-1252.

$\checkmark 4$ McEwen BS: Protective and damaging effects of stress mediators. N Engl J Med 1998; 338:171-179.

5 Baumgart DC, Sandborn WJ: Inflammatory bowel disease: clinical aspects and established and evolving therapies. Lancet 2007; 369:1641-1657.

$\checkmark 6$ Baumgart DC, Carding SR: Inflammatory bowel disease: cause and immunobiology. Lancet 2007;369:1627-1640.

7 Maunder RG, Levenstein S: The role of stress in the development and clinical course of inflammatory bowel disease: epidemiological evidence. Curr Mol Med 2008;8:247-252.

$\checkmark 8$ Farhadi A, Keshavarzian A, Van de Kar LD, Jakate S, Domm A, Zhang L, Shaikh M, Banan A, Fields JZ: Heightened responses to stressors in patients with inflammatory bowel disease. Am J Gastroenterol 2005; 100: 1796-1804.

-9 Andrews H, Barczak P, Allan RN: Psychiatric illness in patients with inflammatory bowel disease. Gut 1987;28:1600-1604.

$\checkmark 10$ Bitton A, Dobkin PL, Edwardes MD, Sewitch MJ, Meddings JB, Rawal S, Cohen A, Vermeire S, Dufresne L, Franchimont D, Wild GE: Predicting relapse in Crohn's disease: a biopsychosocial model. Gut 2008;57:13861392. ing NT, Wilson IG, Holtmann GJ, Andrews JM: Does psychological status influence clinical outcomes in patients with inflammatory bowel disease (IBD) and other chronic gastroenterological diseases: an observational cohort prospective study. Biopsychosoc Med 2008;2:11-19.

-12 Maunder RG, Greenberg GR, Hunter JJ, Lancee WJ, Steinhart AH, Silverberg MS: Psychobiological subtypes of ulcerative colitis: pANCA status moderates the relationship between disease activity and psychological distress. Am J Gastroenterol 2006;101: 2546-2551.

-13 Maunder RG, Greenberg GR, Nolan RP, Lancee WJ, Steinhart AH, Hunter JJ: Autonomic response to standardized stress predicts subsequent disease activity in ulcerative colitis. Eur J Gastroenterol Hepatol 2006;18:413-420.

14 Mawdsley JE, Macey MG, Feakins RM, Langmead L, Rampton DS: The effect of acute psychologic stress on systemic and rectal mucosal measures of inflammation in ulcerative colitis. Gastroenterology 2006;131: 410-419.

15 Vidal A, Gomez-Gil E, Sans M, Portella MJ, Salamero M, Pique JM, Panes J: Life events and inflammatory bowel disease relapse: a prospective study of patients enrolled in remission. Am J Gastroenterol 2006;101:775781.

16 Persoons P, Vermeire S, Demyttenaere K, Fischler B, Vandenberghe J, Van Oudenhove L, Pierik M, Hlavaty T, Van Assche G, Noman M, Rutgeerts P: The impact of major depressive disorder on the short- and longterm outcome of Crohn's disease treatment with infliximab. Aliment Pharmacol Ther 2005;22:101-110.
17 Mardini HE, Kip KE, Wilson JW: Crohn's disease: a two-year prospective study of the association between psychological distress and disease activity. Dig Dis Sci 2004;49: 492-497.

18 Mittermaier C, Dejaco C, Waldhoer T, Oefferlbauer-Ernst A, Miehsler W, Beier M, Tillinger W, Gangl A, Moser G: Impact of depressive mood on relapse in patients with inflammatory bowel disease: a prospective 18-month follow-up study. Psychosom Med 2004;66:79-84.

19 Bitton A, Sewitch MJ, Peppercorn MA, deB Edwardes MD, Shah S, Ransil B, Locke SE: Psychosocial determinants of relapse in ulcerative colitis: a longitudinal study. Am J Gastroenterol 2003;98:2203-2208.

20 Levenstein S, Prantera C, Varvo V, Scribano ML, Andreoli A, Luzi C, Arca M, Berto E, Milite G, Marcheggiano A: Stress and exacerbation in ulcerative colitis: a prospective study of patients enrolled in remission. Am J Gastroenterol 2000;95:1213-1220.

21 Greene BR, Blanchard EB, Wan CK: Longterm monitoring of psychosocial stress and symptomatology in inflammatory bowel disease. Behav Res Ther 1994;32:217-226.

22 Levenstein S, Prantera C, Varvo V, Scribano ML, Berto E, Andreoli A, Luzi C: Psychological stress and disease activity in ulcerative colitis: a multidimensional cross-sectional study. Am J Gastroenterol 1994;89:12191225.

23 von Wietersheim J, Overbeck A, Kiel K, Kohler T, Jantschek G, Feiereis H: The significance of recurrence-inducing events for patients with chronic inflammatory bowel diseases. Results of a prospective longitudinal study over three years (in German). Psychother Psychosom Med Psychol 1994;44: 58-64. 
-24 von Wietersheim J, Kohler T, Feiereis H: Relapse-precipitating life events and feelings in patients with inflammatory bowel disease. Psychother Psychosom 1992;58:103-112.

-25 Duffy LC, Zielezny MA, Marshall JR, Byers TE, Weiser MM, Phillips JF, Calkins BM, Ogra PL, Graham S: Relevance of major stress events as an indicator of disease activity prevalence in inflammatory bowel disease. Behav Med 1991;17:101-110.

-26 Duffy LC, Zielezny MA, Marshall JR, Weiser MM, Phillips JF, Byers TE, Calkins BM, Graham S, Ogra PL: Lag time between stress events and risk of recurrent episodes of inflammatory bowel disease. Epidemiology 1991;2:141-145.

-27 Garrett VD, Brantley PJ, Jones GN, McKnight GT: The relation between daily stress and Crohn's disease. J Behav Med 1991;14: 87-96.
28 North CS, Alpers DH, Helzer JE, Spitznagel EL, Clouse RE: Do life events or depression exacerbate inflammatory bowel disease? A prospective study. Ann Intern Med 1991;114: 381-386.

29 Riley SA, Mani V, Goodman MJ, Lucas S Why do patients with ulcerative colitis relapse? Gut 1990;31:179-183.

30 Li J, Norgard B, Precht DH, Olsen J: Psychological stress and inflammatory bowel disease: a follow-up study in parents who lost a child in Denmark. Am J Gastroenterol 2004; 99:1129-1133.

31 North CS, Clouse RE, Spitznagel EL, Alpers $\mathrm{DH}$ : The relation of ulcerative colitis to psychiatric factors: a review of findings and methods. Am J Psychiatry 1990;147:974981.
32 North CS, Alpers DH: A review of studies of psychiatric factors in Crohn's disease: etiologic implications. Ann Clin Psychiatry 1994;6:117-124.

33 Babyak MA: What you see may not be what you get: a brief, nontechnical introduction to overfitting in regression-type models. Psychosom Med 2004;66:411-421.

34 Minderhoud IM, Samsom M, Oldenburg B: What predicts mucosal inflammation in Crohn's disease patients? Inflamm Bowel Dis 2007;13:1567-1572.

-35 Pruessner JC, Kirschbaum C, Meinlschmid G, Hellhammer DH: Two formulas for computation of the area under the curve represent measures of total hormone concentration versus time-dependent change. Psychoneuroendocrinology 2003;28:916-931. 